\title{
Social Investment Funds: An Organizational Approach to Improved Development Assistance
}

\author{
William Jack
}

This paper examines the design of social investment funds (SIFS) and explores the ways they affect agents' incentives to propose, select, and implement good projects. Compared with other forms of decentralized service provision, sIFs possess features of administratively delegated authority and deep political devolution. Where existing political institutions fail to deliver assistance to vulnerable groups, a well-designed sif may represent a useful administrative alternative. This article reviews several features that provide incentives for both SIF staff and project beneficiaries and concludes with practical guidelines for designing and appraising social investment funds.

Economists and development practitioners are paying increasing attention to the costs of implementing development assistance relative to the results. For example, although the cost of materials required to immunize children against a broad range of diseases is often trivial, such interventions have had disappointing results. In a particularly sobering and provocative analysis, Filmer and Pritchett (1999) suggest that under current practices, the total cost of averting the death of a child under age five is between $\$ 50,000$ and $\$ 100,000$, far more than the estimates of a few hundred dollars or less that are derived using purely technical data (Jamison and others 1993).

The way services are delivered clearly affects a project's cost and effectiveness. Thus, researchers and policy analysts have gone to considerable effort to investigate the design and performance of alternative institutional structures used to deliver development assistance. Calls for decentralization, local participation, inclusion of nongovernmental organizations (NGOS), local ownership, and good governance have been growing in number and volume, notwithstanding the fact that many of these concepts are difficult to define and measure.

One institution that has received growing attention and funding is the social investment fund (SIF), an administrative vehicle for selecting, funding, and implement- 
ing subprojects. The SIF is often established as a unit within the finance ministry or elsewhere in the central government and is used to channel funds to a large number of projects, typically small in size and local in nature. sifs commonly place a high priority on poverty alleviation, either through the types of projects funded (social sector infrastructure, for example) or the production technology used (subsidized lowskill labor, for example). SIFs have proliferated since the first one was introduced in Bolivia in 1990 as a replacement for Bolivia's Emergency Social Fund (which was in place from 1986 through 1989), and the funds now constitute an increasing fraction of the World Bank's social sector lending in Africa and Latin America. They are also increasingly popular in Eastern Europe and in the countries of the former Soviet Union (Schmidt and Marc 1998) and have been adopted by the international donor community as mechanisms for delivering aid. In at least one country, Egypt, the government has set up social investment funds without external financial support.

This article investigates the design of social investment funds using the tools of contract theory, including the principal-agent paradigm, institutional economics, and the theory of incomplete contracts. These theories, which have been used predominantly to study the internal organization of industrial firms, have recently been adapted to facilitate the study of the internal organization of government (Tirole 1994). Because sIFs are generally intended to pursue the public interest (a goal that may not be attained by the private sector alone), these more recent applications should contribute to their analysis.

The first section provides a brief overview of related organizational concepts in the public sector and discusses how sIFs fit into this institutional framework. I then focus on the incentives of potential project beneficiaries, the control of incentives associated with collusion and corruption, and the need to foster cooperation. Finally, I offer some practical guidelines relating to qualitative features of SIFs that may be useful for development practitioners.

\section{Institutional Design, Decentralization, and SIFS}

The analysis of various organizational structures can be framed in terms of the types of agents that are responsible for making and implementing decisions and the scope of their authority over each type of task (Aghion and Tirole 1997). sifs can be thought of as a form of decentralized service provision that combines elements of a centralized policy with implementation by local administrators who are outside the normal political institutions. The easiest way to define SIFS is by considering them relative to other organizational forms of public institutions.

As Oates (1999) recently observed, decentralization is in vogue. This is particularly true in the development community, which is mindful of the legacy of overcentralized public sectors in many developing and transition countries. The benefits and costs 
of decentralization mirror those of laissez-faire capitalism at the individual level: Better information about project benefits and costs at the local level suggests that decisions will be improved under a decentralized system, but decisions about projects with externalities (that is, benefits or costs to persons not party to the transaction) or distributional effects may not be optimal. These costs of decentralization can be said to arise in general from a misalignment of the objectives of central and local decisionmakers.

Several alternative forms of decentralization have been discussed in the literature (Litvack, Ahmad, and Bird 1998). Analysts often use Rondinelli's (1981, 1989) characterization of three types of decentralization:

- Deconcentration involves a central planner who employs an (assumed obedient) agent to implement central policies.

- Under delegation decisionmaking authority and implementation are transferred to an agent whose performance is monitored by the central planner. When the agent's actions cannot be easily controlled, incentives can be implemented through conditional intergovernmental grants (for example, see Holmstrom 1979, Mirrlees 1971, and Oates 1999).

- Finally, under devolution the authority for decisionmaking and implementation is again transferred to subnational bodies, but the central planner does not attempt to monitor or influence the agent's choices. This regime is characterized by the allocation of authority and is better analyzed within the framework of the incomplete contracts literature (Grossman and Hart 1986; Hart 1995; Hart and Moore 1990). ${ }^{1}$

Where do SIFS fit in this framework? A defining feature of SIFS is that projects are considered for selection on a "demand-driven" basis - that is, in accordance with the requests of local communities and other organizations (Jorgensen, Grosh, and Schacter 1992). A second feature is that the projects are small. Finally, the projects have to comply with some stated criteria. For example, the projects may have to be chosen from a menu of alternatives, have a certain sectoral focus, or have an input-use requirement (see Grosh 1990 for the kinds of projects social investment funds should target).

A useful approach is to focus on the functions of the sIF staff. For clarity, assume for now that a single agent runs the SIF. A comparison with other forms of decentralization then revolves around such questions as how the agent is chosen, what actions the agent can take (that is, the extent of the agent's authority or autonomy), and what type of incentive and reward structure the agent faces.

\section{Who Chooses the Agent?}

Because sIFs are typically administered through the central government, the agent is in a position similar to those in deconcentrated and delegated regimes. This distin- 
guishes the SIF from a politically decentralized system, in which the agent would be chosen by and accountable to a local electorate. Under a sIF citizens are empowered through an alternative route. The agent is chosen by the central government-not by the citizens - but it is the citizens, at least those who are mobilized (through NGos or through local firms), who propose the projects directly. The agent has somewhat limited discretion in choosing among the various proposals.

Of course, shifting the responsibility for project selection to small local groups may entail costs. Some of these involve problems of coordination that are usually best alleviated by the central government. For example, free-riding may lead to a lack of proposals for public goods. Similarly, projects that impose costs (benefits) on outsiders will tend to be proposed more (less) often than is warranted. If the proposed projects are large, they are likely to suffer from one or both of these problems - they will either impose costs on other citizens or be undersupplied because of public goods problems. The smaller the projects, the more likely their costs and benefits will be internalized by the proposers, and the more likely they will be efficiently proposed. Delegation of project selection to a higher-level agent makes sense for larger projects.

These observations about the efficiency of project choices by small local groups have two immediate implications. First, because the SIF forgoes the potential benefits provided through a coordinating agent (such as a locally elected official), it must be presumed that such benefits would have been small, or negative. This would be the case if the mechanism by which local officials were chosen could have been expected to result in the selection of an unqualified administrator. Thus, a sIF may effectively bypass such institutions in communities with a poorly functioning public sector hierarchy, say, due to capture of public officials by local elites possibly arising from a high degree of inequality (Bardhan and Mookherjee 1999). The independence of the SIF in such cases can undermine the longer-term development of local institutional capacity, and one must be sure that the SIF is insulated from the effects of local capture.

The second implication is that the rationale for sIF projects must, by default, be redistributive rather than efficiency enhancing. As noted above, the only projects that are likely to be proposed through a SIF are small ones-indeed, investment criteria often stipulate that projects should be small. But these are precisely the projects one would expect the private sector to be able to supply unaided. Thus, those projects that are proposed either would have been adopted in the absence of the SIF or are too costly for poor households to afford without sIF resources. As long as the projects are small, only the second type of project should be accepted. If the SIF does not have distributional goals, it has little reason to focus on small projects that would otherwise probably have been funded. Finally, for the sIF to be the preferred institutional vehicle for effecting redistribution, it must have a comparative advantage over other institutions in targeting the delivery of services (such as a better knowledge of poverty patterns) and a better ability to implement self-targeting mechanisms (such as public works) (Datt and Ravallion 1994). 


\section{What Is the Scope of the Agent's Authority?}

At one extreme, if the central government has precisely specified the menu of allowable projects (in terms of sectoral focus, types of inputs, and so on), the sIF agent can comply with these rules without having to exercise much discretion. Such precise specification of allowable projects, however, implies that the central government begins with perfect information about all potential projects (or at least can identify a welfare-maximizing set of projects), an assumption that is certainly counterfactual. With incomplete information about the range of good projects, the central government's partition of the universe of projects is likely to be coarse, and within the allowable set, the SIF agent will be required to exercise discretion.

The SIF agent is thus in a situation similar to that of local officials with delegated but not devolved authority. This delegation is accompanied by a set of formal links between the central government and the agent regarding the pool of available investment funds (the size of the SIF budget), their broad range of use (guidelines for the budget's allocation), and the specific rewards to the agent. Within the functional classification of decentralized regimes, the structure of the SIF agent's duties and responsibilities is closest to an administratively decentralized institution to which policy directives from the center are delegated. The agent has discretion for implementing these policies but is not necessarily responsible for developing them. ${ }^{2}$

Of course, a blurred line separates policymaking and implementation authority. The more general and vaguely defined the central policies and objectives, the more local choices about implementation begin to resemble policy formulation. For example, more local discretion is required to implement policies stipulating levels of school enrollments, levels of literacy, or even broader definitions of well-being than is required to comply with a policy target that specifies simply the number of schools. The appropriate scope of authority that the SIF agent should be accorded is an important design issue. One obvious set of factors is the agent's ability to make good decisions about projects and the local groups' ability to propose and implement good projects. Both aspects of this task involve issues of local capacity (possibly identified with human and social capital).

One approach to the question of organizational design is to examine the types of structures that result in good decisions. Sah and Stiglitz $(1986,1988)$, for example, concentrate on the nature of information flows within alternative organizational forms. They model hierarchies, polyarchies, and committees as organizations that aggregate information in different ways and hence arrive at different choices. In particular, in choosing whether to accept a project, some organizational structures (such as hierarchies) require greater consensus than others (such as polyarchies). Hierarchies are thus likely to select fewer bad projects than are polyarchies, but they are also likely to accept fewer good projects. Thus, the relative importance of type I (rejection of good projects) versus type II errors (acceptance of bad ones) will determine 
the appropriate structure for decisionmaking. For example, if it is considered imperative to reach the poor, and the costs of leakage to the nonpoor are of less concern, a relatively flat hierarchy is desirable. Conversely, if budgets are so limited that controlling leakage is paramount, a structure that requires greater consensus may be preferred.

But the implicit view in the Sah and Stiglitz analyses of decisionmakers as passive information processors leaves no room for the effect of incentives and strategic behavior, even though there is increasing recognition that both are central to understanding behavior within organizations. As well as relying on the agents' comparative advantage as the basis for allocating authority, the need to motivate agents in the absence of formal incentive schemes may influence these allocation decisions. These design issues turn on the precise nature of the incentive structure within sIFs.

\section{The Role of Incentives}

Within government organizations, good performance can be rewarded with promotions, tenure, greater responsibility, more interesting work, and less supervision (Aghion and Tirole 1997; Campos and Pradhan 1998). Similarly, agents might be motivated by increased budgets rather than by higher salaries. Indeed, economists of the "public choice" school suggest that public sector bureaucrats are motivated as much by the size of their organizations as by their personal income (Brennan and Buchanan 1980). Furthermore, within public institutions, especially in countries with high levels of corruption, it is the net return to good performance that motivates effort. In some cases low effort is rewarded through corrupt side payments-for example, where an agent allocates funding to projects that are favored by powerful local officials but that are not considered appropriate by the central government. In such circumstances it becomes more costly to provide incentives for effort that contributes to the government's economic management because incentive payments, whether in cash or in kind, must be high enough to trump the returns to corruption. Penalties can reduce these returns, of course, if the chances of detection and conviction are high enough.

Within decentralized institutional structures, incentives can be provided either from the top down or from the bottom up. In deconcentrated and delegated regimes, the central government provides incentives from the top, whereas in devolved regimes, incentives must be generated by local citizens directly, through a monitoring and approval process. Communities with powerful minority elites or without a tradition of political participation might not be able to exert such bottom-up pressure, so devolution must be accompanied by political reforms that ensure that the priorities of local citizens are represented effectively.

Of course, sIFs are potentially vulnerable to capture by local elites. It is natural to assume that such capture has negative effects, for example, misappropriation of re- 
sources by the well-to-do. At least in principle, however, local capture could improve matters for the poor, depending on how the preferences of the local elite and the central government are weighted; the local elite might be more pro-poor than the central elite, for example. Bardhan and Mookherjee (1999) have recently modeled the mechanisms and determinants of local capture. For descriptive purposes, it is sufficient to note that in such cases, SIF agents are answerable to at least two principalsthe central government and local interests. Generally, as Dixit (1997) has shown, when two or more principals try to provide incentives for a single agent, the resulting incentives are weaker than when a single principal acts alone. ${ }^{3}$ There is thus a tradeoff between expanding the scope of participation, that is, enlarging the number of principals, or stakeholders, who can influence the agent's decisions and thereby improve the information on which decisions are made, and generating incentives for the agent.

\section{The Role of SIF Beneficiaries}

Because expanded participation can weaken agents' incentives, it is costly. Proponents of social investment funds, however, have typically urged participatory approaches to development (World Bank 1996). Against the costs of expanded participation must be weighed the potential benefits, including a wider pool of (on average, better) projects and increases in local institutional capacity.

\section{Incentives with Multiple Agents}

In most cases, the project cycle involves not only a principal-agent type of arrangement between the central government and the social investment fund but also a multitiered system of interacting individuals. A SIF may choose the project, but it has to write contracts with or delegate authority to a group or a single subordinate, such as an NGO or a firm to carry out the project. Inputs need to be procured from suppliers, a process that might be undertaken by the sIF or by another intermediary, such as an NGO. In Zambia, for example, procurement is implemented by community groups or project committees responsible for the projects.

An immediate implication of this multitiered structure is that incentive problems may arise between the SIF and the contractor, as well as between the central government and the SIF. In such a situation, one would expect the principal (the central government) to specify the nature of the incentive contract between the sIF and the contractor. If, however, the SIF has better information about the incentives that the contractor faces (for example, outside opportunities), it may be preferable to allow the agent to specify the terms of the contract. Thus, one might recommend that the SIF be given authority to specify the extent of cost recovery through the user charges 
imposed by the contractor and the extent of the community's contribution to recurrent costs. Although most sirs encourage community groups to make visible financial or in-kind contributions to projects, few impose a set percentage. Armenia and Zambia are exceptions, however, requiring a 25 percent cofinancing component.

The most common mechanism for inducing good performance on the part of project participants is the requirement to repay the loan. Virtually all sIF funds are distributed to local communities as central government grants, however, and cost recovery is limited. This subsidization is entirely consistent with the objective of redistributing resources to target groups, but it also means that alternative incentives must be provided. The government may exert pressure on the SIF to monitor the use of funds more closely, but the SIF has little direct incentive to do so if it does not share in the returns from the good performance of the project beneficiaries (if, as noted, they do not charge-and remit - user fees). Incentives for good performance at the project level then must come from dynamic considerations, such as the prospects of future funding from the sIF.

Experience suggests that the incentives employed at the project level have entailed more stick than carrot. On the one hand good performance gives participants access to future funds, but not necessarily under relaxed eligibility requirements. On the other hand, poor performance, particularly by contractors, has led to blacklisting as a form of punishment. Alternatively, the enforcement of good performance can be delegated to local residents and community groups. Thus in Honduras, monthly reports of approved projects -including the amount of money that has been spent, the type of project, the identity of the recipient, and so on-are publicly posted. Poor performance can then lead to social sanctions, perhaps enforced through local media and community organizations.

\section{The Effects of Collusion and Corruption}

Less visible are the episodes of collusion and corruption that can occur in an environment with (potentially many) more than two players. For example, Tirole (1986) examined the design of contracts by a principal who employs both a supervisor and the supervisor's agent. The optimal contract must take into consideration the potential for the supervisor and the agent to collude, and this constraint reduces the degree to which efficient allocations can be implemented.

The literature on incomplete contracts provides further insights. Collusion among agents can lead to changes in the optimal choice of institutional structure in terms of delegated authority and discretion. Laffont and Tirole (1991) examine the case of procurement auctions where the auctioneer has the role of supervisor and controls the allocations of procurement contracts among a number of agents. If collusion is possible between the supervisor and one or more agents, the principal should limit the discretion of the supervisor. This explains why the central government might want to limit the types of projects a SIF can finance to those with easily observable 
characteristics, such as size, sector, and input use. The central government may also seek to restrain collusive tendencies by declining to delegate such decisions as the extent of cost recovery to the SIF. These are specific examples of the more general proposition that the potential for collusion might lead a principal to reduce the discretion afforded a subordinate.

The potential problem of collusion in procurement has led to specific institutional choices. In principle, competitive bidding for procurement contracts is an effective mechanism for ensuring cost-efficient choices of input. But in cases where only a few contractors are available and where they interact repeatedly over time, they might find it relatively easy to rig the bidding process. This prospect has led many sifs to adopt a more centralized approach to procurement by establishing detailed unit-cost databases, eliminating the need to solicit prices from input suppliers. There is clearly some tension between this approach and that of decentralizing input decisions to betterinformed suppliers, but the need to control collusion might mean that some potential production efficiency gains are unobtainable. Honduras has attempted to offset losses from collusion by employing two full-time agents who are responsible for compiling monthly data on unit costs in every province.

In the spirit of cost-benefit analysis, even unproductive collusion (that is, collusion that one would consider corrupt) might still be optimal if the costs of controlling it are too high (Eskeland and Thiele 1999). For example, if collusion is controlled by tight restrictions on the kinds of projects chosen by a SIF, the benefits of decentralized choice might be lost. Retaining these benefits may be worth tolerating some collusion (or its potential). Requiring that projects be small, as sIFs typically do, may be a useful way of increasing the transaction costs associated with collusion while still allowing a wide range of potential projects.

Incentives to collude can be controlled in other ways, and restrictions on the kinds of (verifiable) decisions that intermediary supervisors can take may not be the most efficient. One obvious policy is to make sure that agents have to collude to appropriate rents and that they cannot access those rents unilaterally. SIFs and other organizations address this problem by separating the tasks of appraisal, approval, and supervision. In this sense, introducing some friction into the institution may be good for controlling collusion. For example, in Argentina, the SIF does not formally choose projects: Its role is to appraise projects, and even this function is performed by independent contractual staff, who are paid independently of the project's acceptance or performance. Based on these independent appraisals, projects are selected by a panel consisting of provincial and local government officials, nongovernmental organizations, universities, and civil society representatives. In contrast, the functions of appraisal and approval in Peru are more closely associated, probably because of the more decentralized nature of the sIF itself.

An important insight is that collusion must be enforceable. A formal promise of a payoff by one agent in return for a corrupt action by another must be credible if the 
collusive action is to occur. Understanding the mechanism by which such enforcement is effected may be a way to reduce agents' ability to collude. It is unlikely that such contracts will be enforceable by law (imagine a motorist claiming in court that a police officer reneged on his commitment not to write a speeding ticket). But there are other mechanisms that sustain collusion. The individuals responsible for project implementation may have a reputation for fulfilling promises in return for taking bribes (or for punishing those who don't) in an environment in which colluding parties interact repeatedly over time. The organization's rules therefore might require personnel to be rotated at regular intervals to prevent the development of such longterm relationships. Again, such a solution would clearly be at the expense of the economies associated with more efficient production. For example, the potential efficiency of a SIF whose staff changes every year would be lower than one with agents who are familiar with every component of the project and with every agent in the particular environment in which they work. ${ }^{4}$

\section{Local Capacity Building}

Proponents of sIFs acknowledge that many poor communities face a severe lack of organizational capacity. This handicap constrains local participation even as it supports nontraditional interventions such as sIFs. Giving these communities responsibility for or local ownership of the project might be one way to build organizational capacity that could eventually make SIF interventions unnecessary.

What is the most efficient way to generate the organizational capacity needed to permit target groups that lack experience and resources to express their concerns and reveal their preferences? One way is to educate people by increasing literacy and numeracy. But these are themselves long-term projects and may not necessarily contribute to the kind of capacity required to attract funds. The other way is to exploit the possibility of "learning by doing" by giving communities direct experience in running projects. This approach is thought to be most effective when local capacity can be generated through "ownership." In this context, ownership usually refers loosely to each project as a whole and not only the physical assets associated with the investment. The idea is that such ownership facilitates the community's ability to sustain the current project and to identify and implement further projects. Moreover, ownership provides a strong incentive for individuals and groups to achieve the designated objectives.

Local ownership of development projects can be viewed in two ways. The first interpretation is best illustrated with an example: a project aimed at increasing school attendance. A good project should be designed to act both on the demand and the supply sides, first increasing the willingness of children (reflected in parental choices) to attend school, and second, improving the quality of the school. Part of the supplyside effect might be produced by improving the organization of the school system by, 
say, improving incentives for teachers to show up for class or by appointing a new school principal to increase enrollment. In this context local ownership might mean simply that the central authorities cannot assign the principal to another school district that is also having trouble. Note that the concern is not with the incentives of the school principal but with those of the local community (thought of as a single decisionmaker). The aim is to reform the school environment so that the principal is able to be more productive and thus promote greater enrollments. If high-level civil servants can easily remove the principal from the community, local residents have no incentive to consider reforms to strengthen the principal's role. In this case, local ownership might represent a commitment by the authorities not to interfere with decisions such as curriculum or teachers' responsibilities. Such a commitment can lead to greater risk taking and innovation by local decisionmakers (Aghion and Tirole 1997). Identifying ways to make this commitment credible is part of the challenge of building participation into the project design (World Bank 1996).

A more subtle interpretation of ownership, and one that may underlie some less articulated expressions of its power, is its effects on group - as opposed to individualincentives. According to standard agency theory (see, for example, Holmstrom 1982), group incentives are generally more difficult to generate than individual incentives because of the "public good" nature of each group member's output. At the same time, where members of a group interact repeatedly, cooperative behavior can be sustained, even when the individuals are not altruistic. Ownership that is identified with the conceptual formulation of projects at the group level, including their planning, design, and implementation, may promote an environment in which cooperation can be sustained. That is, even in the absence of potential outside interference (either through expropriation of assets or reversal of local decisions as above), ownership in the sense used here may improve internal incentives within the group. Such cooperation might be identified with the formation of social capital, although it is likely to be effective only when the groups are small.

\section{Capacity Substitution}

Economists are well aware that it is the net effects of public intervention that matter and that crowding out of private sector activities must be anticipated when public projects are undertaken (Devarajan, Squire, and Suthiwart-Narueput 1997). In the context of SIFS as generators of local capacity, the situation is reversed: the SIF might impede the development of or substitute for local government agencies. This dilemma is particularly relevant in SIFs that report directly to high-level central government bureaucrats and ministers, bypassing most of the existing line ministries charged with providing the bulk of public services.

It is important to recall that the goals of development are to improve people's lives, especially the poorest groups, not to improve public institutions. If a sIF is an effective 
mechanism for achieving the underlying goal, it might indeed become a de facto local government of sorts. In some countries, local capacity is sufficiently thin that arguing that sIFs impede the development of local government serves only to obscure the plight of the poor.

From a longer-term perspective, one must ask whether a SIF is the preferred institutional structure rather than some other form of devolved local government. One would hope that as communities grow, their reliance on external funding would decline and that either the SIF projects would need to become self-funding or the SIF itself would be replaced by a more traditional local authority (with powers of taxation). The hope may not coincide with reality, however. For example, Bolivia's Emergency Social Fund was intended to be temporary. Even though it was followed by a SIF that continued to fund some of the same kinds of projects, other parts of the emergency fund were transferred to government agencies: The responsibility for road construction reverted to the ministry of transport; a rural development fund was established to focus on rural projects; and an urban infrastructure fund took over large-scale power and water projects in urban areas. Some attempt was made to train local government agents based on the experience and knowledge gained from the operation of the emergency fund, but with limited success. To the extent that sif funding is erratic and varies according to the vagaries of donor support, short- and medium-term development of complementary local institutions seems a prudent insurance mechanism, if nothing else. Collier (1999) warns, however, that this argument should not be overplayed because aid flows to African countries, for example, are in fact much more reliable than domestically generated revenues.

Of course, there is no particular reason that a SIF must operate independently of existing public institutions. Indeed, acknowledging the potential problem of deteriorating existing public institutional capacity, Barrientos (1999) reports that Chile's social fund has adopted an integrated approach to the delivery of services for poverty alleviation, with regional and municipal government agencies involved in the allocation of funds. Clearly the appropriateness of alternative organizational approaches will be country-specific, depending greatly on the quality of the existing institutions.

\section{Some Conclusions on SIF Design}

Many authors have drawn attention to the fact that institutions and organizations matter (see, for example, Burki and Perry 1998; Savedoff 1998; Savedoff and Spiller 1999). But while advocates tout the merits of social investment funds, their arguments tend to be somewhat vague and rhetorical. Although I have not developed an explicit model of either the internal organization of SIFS or their position within the overall public sector, I have attempted to shed some light on the organizational issues 
they raise, focusing mainly on the need to generate incentives for the various actors involved.

With their emphasis on microlevel participation, SIFs deprive themselves of the coordinating function of representative agents, thus reducing the likelihood that public goods with widespread benefits will be provided. Where local officials do not act in the interests of the poor, the social fund may be explicitly intended to bypass wasteful intermediaries and ensure that funds reach those most in need. Good intentions notwithstanding, one must question the ability of sIFs to provide the social and economic infrastructure on the scale that is probably required for meaningful and sustained poverty alleviation.

As a vehicle for identifying and implementing primarily redistributive projects, a SIF should have a particular capacity to target resource flows, either through surveys that provide useful poverty maps or through more demanding analyses of demand and supply characteristics that enable specific in-kind transfers with low distortionary costs. Links to agencies that have this type of analytical capacity (for example, national statistical offices or ministries of finance) are obviously useful.

The net impact of SIF projects will be a function of the quality of proposals made, the quality of those accepted, and the effectiveness with which they are implemented. Each of these components can be influenced by both the staff of the sIF and the (potential) project beneficiaries. The simple implication of this observation is that the SIF must be designed to ensure that all players have adequate incentives to exert effort in pursuit of these goals.

Because SIF outputs, often realized in the social sectors, are hard to quantify, explicit high-powered incentives are difficult to provide. Implicit incentives, associated with increased authority and flexibility within well-defined bounds, may be more effective in stimulating enterprise and what Campos and Pradhan (1998) identify as an esprit de corps among staff. Similarly, incentives for project beneficiaries can be improved by fostering a sense of ownership - either through a commitment by higher authorities not to expropriate fungible assets or reverse local decisions or as an instrument for fostering cooperation within community groups.

One incentive instrument that relies less on ideas of ownership and is more closely related to traditional principal-agent theory is cost sharing. SIFs might require the project beneficiaries to provide matching funds for certain project components as a way of inducing citizen participation in the implementation effort. Of course, this approach reduces the net transfer to the project, compromising the redistributive impact. Indeed, in using this kind of cofinancing to address a moral hazard issue, the SIF comes up against an adverse selection problem: relatively well-off communities will be better able to comply with cofinancing requirements and thus are more likely to have resources directed to them. Ideally, the cofinancing rate should vary with the ability of the community to generate local funds, but this is only possible if good indicators of local poverty rates are available. 
Other sources of cofinancing might include local governments, procurement agencies, and other line ministries. As a source of additional funding, such cofinancing arrangements are worthwhile, but introducing links with these other agencies would appear to undermine the streamlined structure that SIFs aim to attain. If the cofinancing arrangements are at arm's length, then interference from the other sources may be limited. Once agencies start contributing financial resources to projects, however, they often assume an implicit right to get involved in project choices and other aspects of decisionmaking, such as procurement.

\section{Notes}

William Jack is a visiting professor at Georgetown University. The author thanks Jeni Klugman and Julie van Domelen for helpful comments.

1. An alternative characterization of decentralized systems can be made on a functional basis. Thus Litvack, Ahmad, and Bird (1998) distinguish among three alternatives. (Unlike Rondinelli's characterization, the three components of this functional representation are not necessarily mutually exclusive.)

- Fiscal decentralization is about the assignment of expenditure and taxation authority between levels of government.

- Political decentralization can be thought if as describing the mechanism by which agents that either make policy decisions or implement exogenous policies at the local level are chosen (for example, in local elections, but there are other procedures). Economic conditions (in particular, the extent of income inequality) and social and cultural norms determine the extent to which locally chosen agents are those who will make "good" decisions.

- Administrative decentralization allows local decisions to be acted on. It would be very rare to have locally formulated policies implemented by the central government, but local implementation is possible only where the necessary administrative infrastructure and resources are available.

2. As noted above, in terms of the actions of local groups and citizens, the sIF has features qualitatively similar to a politically decentralized structure.

3. In Dixit's model the agent takes a number of actions or efforts. Principals' preferences over the outcomes of different actions differ. Each principal will then propose a contract that offers the agent more insurance by making payment negatively correlated with performance in dimensions that the principal does not care for. All principals act the same, resulting in a dilution of incentives.

4. A final mechanism by which collusion may be retarded is to make the rewards to agents less responsive to reports to the principal by supervisors. Laffont (1990) shows that even when outcomes of different agents are uncorrelated, making each agent's reward dependent on the aggregate performance of the group reduces the incentive for collusion between the supervisor and the agents.

\section{References}

The word "processed" describes informally reproduced works that may not be commonly available through library systems.

Aghion, Phillipe, and Jean Tirole. 1997. "Formal and Real Authority in Organizations." Journal of Political Economy 105(1):1-29. 
Bardhan, Pranab, and Dilip Mookherjee. 1999. "Relative Capture of Local and Central Governments: An Essay in the Political Economy of Decentralization." University of California, Department of Economics, Berkeley. Processed.

Barrientos, Jorge C. 1999. "Coordinating Poverty Alleviation Programs with Regional and Local Governments: The Experience of the Chilean Social Fund (Fosis)." Report prepared for the Human Development Network, Social Protection Team, World Bank. Washington, D.C. Processed.

Brennan, Geoffrey, and James M. Buchanan. 1980. The Power to Tax: Analytical Foundations of a Fiscal Constitution. Cambridge, Mass.: Cambridge University Press.

Burki, Shahid Javed, and Guillermo E. Perry, eds. 1998. Beyond the Washington Consensus: Institutions Matter. Washington, D.C.: World Bank.

Campos, J. Edgardo, and Sanjay Pradhan. 1998. "Building Blocks toward a More Effective Public Sector.” EDI working paper. World Bank, Economic Development Institute, Washington, D.C. Processed.

Collier, Paul. 1999. “Aid and Dependency: A Critique.” Journal of African Economies 8(4):528-45.

Datt, Gaurav, and Martin Ravallion. 1994. "Transfer Benefits from Public Works Employment: Evidence for Rural India." Economic Journal 104(November):1346-69.

Devarajan, Shantayanan, Lyn Squire, and Sethaput Suthiwart-Narueput. 1997. "Beyond Rate of Return: Reorienting Project Appraisal.” World Bank Research Observer 12(1):35-46.

Dixit, Avinash. 1997. "Power of Incentives in Private versus Public Organizations." American Economic Review 87(May):378-82.

Eskeland, Gunnar, and Henrick Thiele. 1999. "Corruption under Moral Hazards.” Policy Research Working Paper 2204. World Bank, Development Economics Research Group, Washington, D.C. Processed.

Filmer, Deon, and Lant Pritchett. 1999. "The Impact of Public Spending on Health: Does Money Matter?" Social Science and Medicine 49(10):1309-23.

Grosh, Margaret. 1990. "What Should Social Funds Finance?: Portfolio Mix, Targeting, and Efficiency Criteria.” LAтHR 3. World Bank, Human Resources Division, Latin America and the Caribbean, Washington, D.C. Processed.

Grossman, Sanford, and Oliver Hart. 1986. "The Costs and Benefits of Ownership: A Theory of Vertical and Lateral Integration." Journal of Political Economy 94(4):691-719.

Hart, Oliver. 1995. Firms, Contracts, and Financial Structure. New York: Oxford University Press.

Hart, Oliver, and John Moore. 1990. "Property Rights and the Nature of the Firm.” Journal of Political Economy 98(6):1119-58.

Holmstrom, Bengt. 1982. "Moral Hazard in Teams.” Bell Journal of Economics 13:324-40.

Jamison, Dean, W. Henry Mosley, Anthony Measham, and Jose-Louis Bobadilla, eds. 1993. Disease Control Priorities in Developing Countries. Oxford: Oxford Medical Publications.

Jorgensen, Steen, Margaret Grosh, and Mark Schacter, eds. 1992. Bolivia's Answer to Poverty, Economic Crisis, and Adjustment: The Emergency Social Fund. Washington, D.C.: World Bank.

Laffont, Jean-Jacques. 1990. “Analysis of Hidden Gaming in a Three Level Hierarchy.” Journal of Law, Economics, and Organization 6(2):301-24.

Laffont, Jean-Jacques, and Jean Tirole. 1991. “Auction Design and Favoritism.” International Journal of Industrial Organization 9:9-42.

Litvack, Jennie, Junaid Ahmad, and Richard Bird. 1998. "Rethinking Decentralization in Developing Countries." World Bank Sector Study, Poverty Reduction and Economic Management Network, Washington, D.C. Processed.

Mirrlees, James. 1971. "An Exploration in the Theory of Optimum Income Taxation.” Review of Economic Studies 38:175-208. 
Oates, Wallace. 1999. “An Essay in Fiscal Federalism.” Journal of Economic Literature 37(3):1120-49. Rondinelli, Dennis. 1981. "Government Decentralization in Comparative Perspective: Theory and Practice in Developing Countries.” International Review of Administrative Sciences 47(2):133-45.

—. 1989. "Decentralizing Urban Development Programs: A Framework for Analyzing Policy." U.S. Agency for International Development, Office of Housing and Urban Programs, Washington, D.C.

Sah, Raaj Kumar, and Joseph E. Stiglitz. 1986. "The Architecture of Economic Systems: Hierarchies and Polyarchies.” American Economic Review 76(4):716-27.

- 1988. "Committees, Hierarchies, and Polyarchies.” Economic Journal 98:451-70.

Savedoff, William, ed. 1998. Organization Matters: Agency Problems in Health and Education in Latin America. Washington, D.C.: Inter-American Development Bank.

Savedoff, William, and Pablo Spiller. 1999. Spilled Water: Institutional Commitment in the Provision of Water Services. Washington, D.C.: Inter-American Development Bank, Latin American Research Network.

Schmidt, Mary Beth, and Alexander Marc. 1998. "Social Investment Funds in Transition Economies: Opportunities and Risks.” World Bank, Washington, D.C. Processed.

Tirole, Jean. 1986. "Hierarchies and Bureaucracies: On the Role of Collusion in Organizations." Journal of Law, Economics, and Organization 2(2):181-214.

—. 1994. "The Internal Organization of Government." Oxford Economic Papers 46:1-34.

World Bank. 1996. The World Bank Participatory Sourcebook. Washington, D.C. 